\title{
Long-term secondary prevention of acute myocardial infarction (SEPAT) - guidelines adherence and outcome
}

Constantinos Ergatoudes ${ }^{1} \mathbb{B}$, Erik Thunström¹, Annika Rosengren ${ }^{1}$, Lena Björck ${ }^{1,2}$, Kristina Bengtsson Boström³ Kristin Falk ${ }^{2}$ and Michael Fu ${ }^{1,4^{*}}$

\begin{abstract}
Background: A number of registry studies have reported suboptimal adherence to guidelines for cardiovascular prevention during the first year after acute myocardial infarction (AMI). However, only a few studies have addressed long-term secondary prevention after AMI. This study evaluates prevention guideline adherence and outcome of guideline-directed secondary prevention in patients surviving 2 years after AMI.

Methods: Patients aged 18-85 years at the time of their index AMI were consecutively identified from hospital discharge records between July 2010 and December 2011 in Gothenburg, Sweden. All patients who agreed to participate in the study (16.2\%) were invited for a structured interview, physical examinations and laboratory analysis 2 years after AMI. Guideline-directed secondary preventive goals were defined as optimally controlled blood pressure, serum cholesterol, glucose, regular physical activity, smoking cessation and pharmacological treatment.

Results: The mean age of the study cohort $(n=200)$ at the index AMl was $63.0 \pm 9.7$ years, $79 \%$ were men. Only $3.5 \%$ of the cohort achieved all six guideline-directed secondary preventive goals 2 years after infarction. LDL $<1.8 \mathrm{mmol} / \mathrm{L}$ was achieved in $18.5 \%$ of the cohort, regular exercise in $45.5 \%$ and systolic blood pressure $<140 \mathrm{mmHg}$ in $57.0 \%$. Anti-platelet therapy was used by $97 \%$ of the patients, beta-blockers by $83.0 \%$, angiotensinconverting enzyme inhibitors/angiotensin receptor blockers by $76.5 \%$ and statins by $88.5 \%$. During follow-up, nonfatal adverse cardiovascular events (cardiac hospitalization, recurrent acute coronary syndrome, angina pectoris, new percutaneous coronary intervention, new onset of atrial fibrillation, post-infarct heart failure, pacemaker implantation, stroke/transient ischemic attack (TIA), cardiac surgery and cardiac arrest) occurred in $47 \%$ of the cohort and readmission due to cardiac causes in 30\%.
\end{abstract}

Conclusions: Our data showed the failure of secondary prevention in our daily clinical practice and high rate of non-fatal adverse cardiovascular events 2 years after AMI.

Keywords: Secondary prevention, Cardiovascular disease, Myocardial infarction, Long-term

\footnotetext{
* Correspondence: Michael.fu@vgregion.se

'Department of Molecular and Clinical Medicine, Institute of Medicine,

Skövde, Sweden

${ }^{4}$ Department of Medicine, Section of Cardiology, Sahlgrenska University

Hospital/Östra, 41651 Göteborg, Sweden

Full list of author information is available at the end of the article
} 


\section{Background}

The main purpose of secondary prevention after acute myocardial infarction (AMI) is to reduce recurrence, decrease morbidity and mortality and improve quality of life. To achieve these goals, available guidelines for cardiovascular prevention worldwide uniformly recommend lifestyle interventions: smoking cessation, increased physical activity, maintaining a healthy body mass index (BMI), optimal control of risk factors (blood pressure, cholesterol and glucose control) and optimal use of cardio protective drug therapies (aspirin, beta-blockers, angiotensinconverting enzyme (ACE) inhibitors/angiotensin II receptor blockers (ARBs), lipid-lowering drugs) [1-5].

During the past decades, several studies have repeatedly demonstrated suboptimal adherence to guidelines in patients after AMI. EUROASPIRE (European Action on Secondary and Primary Prevention by Intervention to Reduce Events) I-IV surveys showed that a large majority of coronary artery disease patients did not achieve the standard of secondary prevention stipulated by the guidelines (1-5). The prevalence of smoking, poor diet and physical inactivity remains high and most patients remain overweight or obese with a high prevalence of diabetes. Moreover, despite increasing use of medications, risk factor control remains suboptimal [6-8]. A recent Swedish study showed that risk factor control has improved slightly over time after AMI, but improvement was mainly seen in control of blood pressure, indicating substantial potential for improvement in other preventive goals $[9,10]$.

Persistent secondary prevention is warranted after AMI for long-term cardiovascular protection. However, available studies that have evaluated secondary prevention have mainly been done up to within 1 year post AMI. Moreover, most studies have been registry-based, where data are often restricted and less detailed. Consequently, knowledge about secondary prevention 2 years post-AMI is limited. The main objectives of the current study were therefore to evaluate adherence to secondary prevention guidelines and outcome 2 years after AMI.

\section{Methods}

\section{Patients}

We included consecutive men and women who had undergone AMI, were aged $\geq 18$ years and $<85$ years at the time of their index event and who were still alive 2 years post-AMI. The patients were identified retrospectively from hospital discharge lists. All participants were living in the catchment area of Gothenburg and had been hospitalized for AMI at Sahlgrenska University Hospital Östra or Sahlgrenska University Hospital/Sahlgrenska between July 2010 and December 2011. The diagnosis of AMI was based on the following criteria: at least one value of troponin level $>15 \mathrm{ng} / \mathrm{L}$ and at least one of the following: chest pain, newly discovered ECG changes (pathological ST/T-wave, left bundle branch block or a pathological Q-wave), regional wall motion abnormality in the left ventricle discovered by echocardiography or MRI or proven intracoronary thrombosis or stenosis by coronary angiography [11]. Patients unable to speak or understand Swedish were excluded.

\section{Structured interview}

A personal interview was conducted by experienced nurses at a minimum of 2 years after the index AMI event. A detailed questionnaire containing pre-defined questions was used that included information on marital status, living situation, education, occupation, past illnesses, chest pain and shortness of breath, depression, medication, smoking, use of Swedish snus, alcohol use, stress and exercise. The questionnaire was completed under supervision of the research staff.

Higher education was defined as having a university degree. Employment was coded dichotomously (working or not working). Smoking was defined as never smoked; yes, regularly; yes, sometimes; no, quit smoking. Quit smoking was defined as trying to quit during the 2 weeks preceding the interview. Depression was defined as feeling depressed for more than 2 consecutive weeks during the past 12 months. Self-perceived stress was defined as permanent stress during the last 5 years [12] Self-reported physical activity during leisure time was categorized into four levels according to a modified version of Saltin-Grimby Physical Activity Level Scale (SGPALS) [13]: sedentary; moderate physical activity at least $2 \mathrm{~h}$ per week (without sweating); regular physical activity (1-2 times per week); vigorous physical activity for at least 3 times per week.

\section{Structured examinations}

A variety of variables were measured, including height, weight, waist circumference, hip circumference, blood pressure and ECG. Body height was measured to the nearest $1 / 2 \mathrm{~cm}$ and weight to $0.1 \mathrm{~kg}$ (Tanita Corporation, Tokyo, Japan), with the subjects in light clothing and without shoes. BMI was calculated as weight $(\mathrm{kg}) /$ height (m) squared. Waist was defined as the area between the iliac crest and to the approximate area of the lowest rib. Hip circumference was measured as the widest circumference around the hips. Resting ECG was taken with a 12-lead ECG (Cardiolex, Solna, Sweden). Blood pressure was measured twice for each person after a 5-min rest with the person in a sitting position using the Omron HEM-907 IntelliSense professional digital blood pressure monitor (Omron Corporation, Omuro, Kyoto, Japan).

\section{Laboratory analyses}

Fasting blood samples were collected for analysis of hemoglobin, low-density lipoprotein (LDL) cholesterol, 
high-density lipoprotein (HDL) cholesterol, total triglycerides, total serum cholesterol, ApoB/ApoA1 ratio, glycated hemoglobin $\mathrm{HbA1c}$, blood glucose, potassium, sodium and creatinine. HbA1c was measured in all participants because $\mathrm{HbA} 1 \mathrm{C}$ is widely accepted as one of diagnostic criteria for diabetes. As long as patients have HbA1c $<48 \mathrm{mmol} / \mathrm{mol}$ they have achieved goals regardless of diabetes or not. Serum and plasma were aliquoted and stored at a $-80{ }^{\circ} \mathrm{C}$ until analysed. All laboratory analyses were done at the Department of Clinical Chemistry, Sahlgrenska University Hospital, Gothenburg, Sweden.

\section{Data from medical records}

A retrospective review of medical records was conducted to collect data on demographic details, medical history, diagnostic test results (e.g., ECG, echocardiography and coronary angiogram), treatments and outcome data.

\section{Outcome measures}

The primary outcome measure was the proportion of patients with AMI who achieved the stipulated secondary preventive guideline recommendations, categorized as six variables (Table 1). The secondary outcome measure was non-fatal adverse cardiovascular events 2 years after AMI.

The definitions for achieving a guideline standard are presented in Table 1 [3]. Non-fatal cardiovascular events were defined as all cardiovascular events that occurred after the index AMI, including recurrent acute coronary syndrome, angina pectoris, new onset of atrial fibrillation, post-MI heart failure, percutaneous coronary intervention (PCI), cardiac arrest, stroke/TIA and any readmission secondary to cardiac disease. Post-MI heart failure was defined as a newly developed clinical manifestation of heart failure based on heart failure symptoms in combination with either increased NT pro BNP $>300 \mathrm{pg} / \mathrm{ml}$ or LVEF $<40 \%$ after AMI. Angina pectoris was defined as $\geq$ class 2 based on the Canadian Cardiovascular Society Angina Grading Scale (CCS

Table 1 Secondary prevention guidelines after AMI

\begin{tabular}{|c|c|}
\hline 1 & $\begin{array}{l}\text { Optimally controlled blood pressure, defined } \\
\text { as SBP }<140 \mathrm{mmHg}\end{array}$ \\
\hline 2 & $\begin{array}{l}\text { Optimally controlled cholesterol levels, defined } \\
\text { as } L D L \text { cholesterol }<1.8 \mathrm{mmol} / \mathrm{L}\end{array}$ \\
\hline 3 & $\begin{array}{l}\text { Optimally controlled glucose, defined as } \mathrm{HbA} 1 \mathrm{c} \\
<48 \mathrm{mmol} / \mathrm{mol}\end{array}$ \\
\hline 4 & $\begin{array}{l}\text { Regular physical activity that caused sweating } \\
\text { at least two times a week }\end{array}$ \\
\hline 5 & $\begin{array}{l}\text { Smoking cessation, defined as non-smoking } \\
\text { at the time of the interview }\end{array}$ \\
\hline 6 & $\begin{array}{l}\text { Pharmacological treatment with ACE inhibitors } \\
\text { or ARBs }\end{array}$ \\
\hline
\end{tabular}

$A M I$ acute myocardial infarction, SBP systolic blood pressure, $L D L$ low-density lipoprotein, $A C E$ angiotensin-converting enzyme, ARB angiotensin II receptor blockers
Angina Grading Scale) [14]. Cardiac readmissions were all readmissions due to any cardiac cause (according to The International Classification of Diseases ICD-10).

\section{Statistical analyses}

Data are reported as frequency and percentage for categorical variables and mean with standard deviation for quantitative variables. Data were analysed using IBM SPSS Statistics 22.0 (IBM Corp., Chicago, ILL, USA).

\section{Ethics}

This study complies with the Declaration of Helsinki [15] and the study protocol was approved by the Ethics Committee of the Medical Faculty of the University of Gothenburg. Written informed consent was obtained from each participant by the principal investigator. The research assistants signed the Case Report Form to confirm that informed consent was obtained.

\section{Results \\ Study cohort}

In total, 1234 patients were hospitalized with an AMI in the area of Gothenburg between July 2010 and December 2011. Of those 1234 patients, 860 were excluded from the study because of various reasons (Fig. 1). After excluding all participants that either did not meet the inclusion criteria, or who could not be accessed, 374 patients were eligible. Of those, 56 patients did not sign the informed consent form or declined further participation and 118 did not respond to the invitation. Thus, the final sample included 200 patients (Fig. 1).

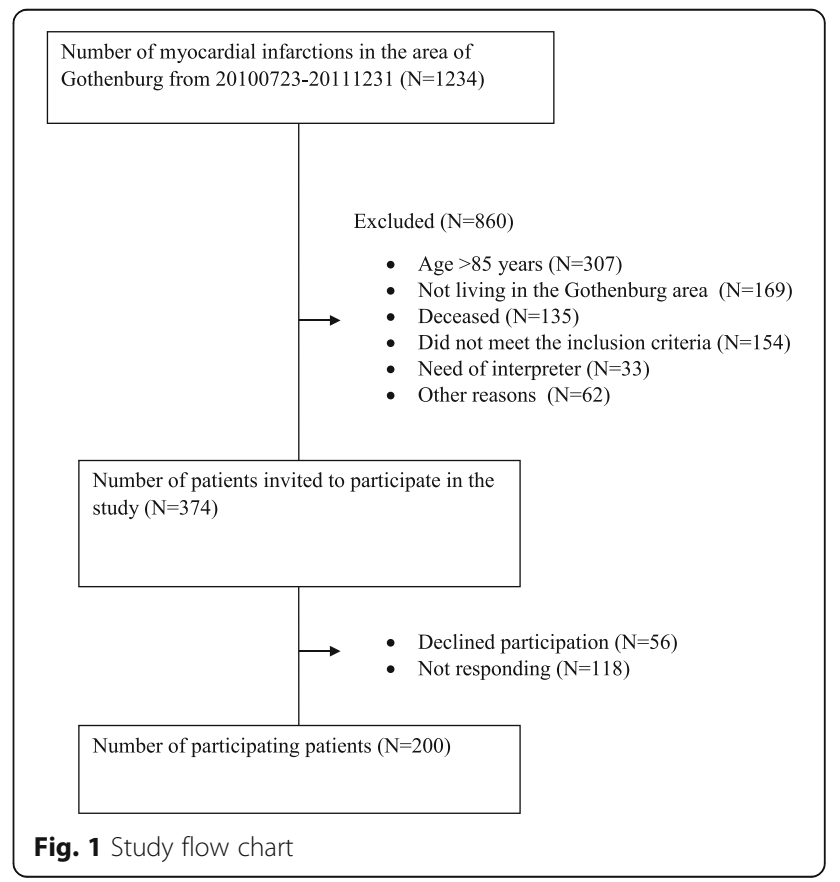


Baseline characteristics at the time of the index AMI At the time of the index AMI, 69\% of the patients had ST-segment elevation myocardial infarction (STEMI), $31 \%$ a non-STEMI (NSTEMI). Mean heart rate was 75.6 (SD \pm 18.8 ) beats/min, mean systolic blood pressure (SBP) 146.1 (SD \pm 25.7$) \mathrm{mmHg}$ and mean diastolic blood pressure (DBP) 91.3 (SD \pm 15.0$) \mathrm{mmHg}$. Almost everyone that was included (96\%) underwent a percutaneous coronary intervention (PCI) or a coronary artery bypass grafting (CABG) in association with the index event.

\section{Demographic characteristics at interview}

The mean age of the study cohort at follow-up $(n=200)$ was $65.5(\mathrm{SD} \pm 9.8)$ years and $79 \%$ were male (Table 2 ). Moreover, $79.3 \%$ were born in Sweden, $23.5 \%$ had a higher education and $34.4 \%$ were still actively working.

\section{Lifestyle characteristics and psychological conditions at interview}

As shown in Table 2, a minority of the patients were still smokers (12.5\%) regularly or occasionally; however, most of these patients had smoked at some time in their life (69\%). Only one of seven patients reported a sedentary lifestyle 2 years after their index AMI, whereas $40.5 \%$ claimed to engage in moderate physical exercise without sweating, 25\% did moderate exercise with sweating and $20.5 \%$ participated in regular physical exercise and training. Concerning psychological factors, $15 \%$ of the patients had been depressed during the past year and almost $10 \%$ had felt constantly stressed during the past 5 years. Feeling stressed and depressed were more common in those aged $<65$ years. Almost 20\% of the patients $<65$ years of age had been constantly stressed for the past 5 years, whereas only $2 \%$ of those aged $>65$ years had felt stressed during the same period.

\section{Clinical characteristics based on interview, review of medical records and physical examinations}

The two most common comorbidities were hypertension (63.4\%) and hyperlipidemia (63.9\%), followed by diabetes mellitus (21.8\%) and atrial fibrillation (14.8\%). Medical records showed that $22.5 \%$ of the patients were still smoking at the time of the index AMI, 13\% had at least one previous myocardial infarction and $11.5 \%$ underwent PCI (Table 2).

At the physical examination, which was given during the interview, mean SBP was $137.5 \mathrm{mmHg}$ and mean DBP $79.6 \mathrm{mmHg}$ respectively (Table 3 ). Sinus rhythm constituted $93 \%$ with a mean heart rate at approximately 59.0 beats/minute. $17.5 \%$ of the study population had a BMI over $30 \mathrm{~kg} / \mathrm{m}^{2}$
Table 2 Social and clinical characteristics of patients at the time of the interview 2 years after AMl

\begin{tabular}{|c|c|c|c|}
\hline \multirow[b]{2}{*}{ Variables } & \multicolumn{3}{|l|}{ Groups } \\
\hline & $\begin{array}{l}\text { All } \\
N=200\end{array}$ & $\begin{array}{l}\text { Men } \\
N=158\end{array}$ & $\begin{array}{l}\text { Women } \\
N=42\end{array}$ \\
\hline Age, years, mean $\pm S D$ & $65.5 \pm 9.8$ & $64.7 \pm 9.5$ & $68.2 \pm 10.2$ \\
\hline \multicolumn{4}{|l|}{ Social factors } \\
\hline $\begin{array}{l}\text { Born in Sweden } \\
n=199(\%)\end{array}$ & $158(79.3)$ & $123(77.8)$ & $35(83.3)$ \\
\hline $\begin{array}{l}\text { Higher education }^{a} \\
n=200(\%)\end{array}$ & $47(23.5)$ & $35(22.2)$ & $12(28.6)$ \\
\hline $\begin{array}{l}\text { Currently working } \\
n=199(\%)\end{array}$ & $72(34.4)$ & $62(39.2)$ & $10(23.8)$ \\
\hline \multicolumn{4}{|l|}{ Smoking $^{a} n=200$} \\
\hline Never (\%) & $62(31.0)$ & $45(28.5)$ & $17(40.5)$ \\
\hline Regularly (\%) & $13(6.5)$ & $13(8.2)$ & $0(0.0)$ \\
\hline Sometimes (\%) & $12(6.0)$ & $11(7.0)$ & $1(2.4)$ \\
\hline Quit (\%) & $113(56.5)$ & $89(56.3)$ & $24(57.1)$ \\
\hline \multicolumn{4}{|l|}{ Exercise $^{\mathrm{a}} n=200$} \\
\hline Sedentary n (\%) & $28(14)$ & $18(11.4)$ & $10(23.8)$ \\
\hline Moderate activity n (\%) & $81(40.5)$ & $63(39.9)$ & $18(42.9)$ \\
\hline Regular activity $n,(\%)$ & $50(25.5)$ & $41(35.9)$ & $9(21.4)$ \\
\hline Vigorous activity n, (\%) & $41(20.5)$ & $36(22.8)$ & $5(11.9)$ \\
\hline \multicolumn{4}{|l|}{ Cardiovascular diseases } \\
\hline $\begin{array}{l}\text { Atrial fibrillation }{ }^{a} \\
n=196(\%)\end{array}$ & $29(14.8)$ & $19(12.3)$ & $10(24.4)$ \\
\hline $\begin{array}{l}\text { Known heart failure } \\
n=193(\%)\end{array}$ & $16(8.3)$ & $10(6.5)$ & $6(15.8)$ \\
\hline $\begin{array}{l}\text { Hypertension }^{a} \\
n=194(\%)\end{array}$ & $123(63.4)$ & $93(61.2)$ & $30(71.4)$ \\
\hline Diabetes $^{\mathrm{a}} n=197(\%)$ & $43(21.8)$ & $37(23.6)$ & $6(15)$ \\
\hline Stroke/TIA ${ }^{a} n=198(\%)$ & $14(7.2)$ & $12(7.7)$ & $2(4.9)$ \\
\hline $\begin{array}{l}\text { Hyperlipidemia }{ }^{a} \\
n=180(\%)\end{array}$ & $115(63.9)$ & $90(63.4)$ & $25(65.8)$ \\
\hline Previous MI $n=200(\%)$ & $26(13.0)$ & $19(12.0)$ & $8(19.0)$ \\
\hline Previous PCI $n=200$ (\%) & $23(11.5)$ & $18(11.4)$ & $5(11.9)$ \\
\hline \multicolumn{4}{|l|}{ Non-cardiovascular disease } \\
\hline Cancer $^{\mathrm{a}} n=200(\%)$ & $31(15.5)$ & $22(13.9)$ & $9(21.4)$ \\
\hline COPD $n=193(\%)$ & $39(20.2)$ & $29(19.1)$ & $10(24.4)$ \\
\hline OSA $n=162(\%)$ & $48(29.6)$ & $37(29.6)$ & $11(29.7)$ \\
\hline $\begin{array}{l}\text { Renal failure GFR }<60 \\
n=200(\%)\end{array}$ & $55(27.5)$ & $33(20.1)$ & $18(42.9)$ \\
\hline $\begin{array}{l}\text { Renal failure GFR }<30 \\
n=200(\%)\end{array}$ & $4(2)$ & $4(2.5)$ & $0(0.0)$ \\
\hline $\begin{array}{l}\text { Depressed for at least } \\
2 \text { consecutive weeks in the } \\
\text { past } 12 \text { months } n=200(\%)\end{array}$ & $30(15)$ & $20(12.7)$ & $10(23.8)$ \\
\hline
\end{tabular}

Data were presented as $\mathrm{n}(\%)$

TIA transient ischemic attack, $M I$ myocardial infarction, $P C l$ percutaneous coronary intervention, COPD chronic obstructive pulmonary disease, OSA obstructive sleep apnea

${ }^{a}$ Self-specified answers to questions in the SEPAT questionnaire 
Table 3 Physical examination and laboratory analysis at the time of the interview 2 years after the index AMI event

\begin{tabular}{|c|c|c|c|}
\hline & \multicolumn{3}{|l|}{ Groups } \\
\hline & $\begin{array}{l}\text { All } \\
N=200\end{array}$ & $\begin{array}{l}\text { Men } \\
N=158\end{array}$ & $\begin{array}{l}\text { Women } \\
N=42\end{array}$ \\
\hline $\mathrm{SBP}(\mathrm{mmHg})$ & $137.5(18)$ & $138.3(18.3)$ & $134.2(16.4)$ \\
\hline $\mathrm{DBP}(\mathrm{mmHg})$ & $79.6(10.3)$ & $80.7(10.0)$ & $75.5(10.5)$ \\
\hline HR (beats/minute) & $59.7(10.7)$ & $59.1(10.8)$ & $61.9(10.2)$ \\
\hline Weight (Kg) & $84.7(16.2)$ & $86.9(15.4)$ & $76.4(16.3)$ \\
\hline \multicolumn{4}{|l|}{ BMI } \\
\hline $\begin{array}{l}25 \mathrm{~kg} / \mathrm{m}^{2}<\mathrm{BMl} \\
\leq 30 \mathrm{~kg} / \mathrm{m}^{2}(\%)\end{array}$ & 47.0 & 50.6 & 35.7 \\
\hline$>30$ kg/m² (\%) & 25.5 & 20.9 & 40.5 \\
\hline Waist (cm) & $100.2(12.4)$ & $101.4(11.0)$ & $95.7(16.1)$ \\
\hline \multicolumn{4}{|l|}{ Lab } \\
\hline $\mathrm{HbA1c}(\mathrm{mmol} / \mathrm{L})$ & $40.5(9.3)$ & $39.8(8.8)$ & $43.0(10.5)$ \\
\hline Cholesterol (mmol/L) & $4.1(1.0)$ & $4.1(0.9)$ & $4.5(1.2)$ \\
\hline LDL (mmol/L) & $2.4(0.9)$ & $2.4(0.8)$ & $2.6(1.1)$ \\
\hline $\mathrm{HDL}(\mathrm{mmol} / \mathrm{L})$ & $1.4(0.6)$ & $1.4(0.4)$ & $1.6(0.5)$ \\
\hline ApoB/ApoA1 quote & $0.6(0.2)$ & $0.6(0.2)$ & $0.5(0.2)$ \\
\hline Triglycerides (mmol/L) & $1.3(0.6)$ & $1.3(0.6)$ & $1.3(0.5)$ \\
\hline P-glucose (mmol/L) & $5.7(1.3)$ & $5.7(1.3)$ & $5.7(1.3)$ \\
\hline NTproBNP (pg/ml) & $396.8(750.7)$ & $344.1(682.3)$ & $594.9(949.6)$ \\
\hline $\begin{array}{l}\text { NTproBNP } \\
>300 \text { pg/ml (\%) }\end{array}$ & 31.5 & 25.3 & 44.2 \\
\hline
\end{tabular}

Data were presented as $\mathrm{n}(\%)$, otherwise in mean (SD). SBP systolic blood pressure, DBP diastolic blood pressure, $H R$ heart rate, $B M I$ body mass index $L D L$ low density lipoprotein, $H D L$ high density lipoprotein

\section{Non-fatal cardiovascular events}

During the 2-year study period non-fatal cardiovascular events occurred in $46.5 \%$ of the participants. Readmissions due to all causes were $50.5 \%$ and due to cardiac disease 30\%. Among them, new AMIs constituted 8\%, new PCIs $11.5 \%$, atrial fibrillation $7.5 \%$, TIA/stroke $6 \%$, cardiac arrest $1 \%$, post-infarction heart failure $19.5 \%$ and cardiac surgery $9.5 \%$ (Table 4). It is noteworthy to mention that the number of cardiac events may outnumber readmission rate since several events may occur during the same readmission. Our study was not powered to assess the causal relation between increased non-fatal cardiovascular events and suboptimal secondary prevention.

\section{Achievements of guideline standards in secondary prevention}

As shown in Table 5, the goal of SBP was achieved in $57 \%$ of the patients, $18.5 \%$ had LDL of $<1.8 \mathrm{mmol} / \mathrm{L}$, $87.5 \%$ did not smoke, $45.5 \%$ achieved the goal defined by regular exercise with sweating. The goal for HbA1c was achieved in almost $90 \%$ of the patients; however, most of these patients did not have diabetes. ACE inhibitor/ARB
Table 4 Non-fatal cardiovascular events during the 2-year follow-up after the index AMl event

\begin{tabular}{|c|c|}
\hline Readmissions, all cause, $n(\%)$ & $101(50.5)$ \\
\hline Readmissions, cardiac, n (\%) & $60(30.0)$ \\
\hline Recurrent myocardial infarction, $n(\%)$ & $16(8.0)$ \\
\hline Unstable angina, $n(\%)$ & $8(4.0)$ \\
\hline $\mathrm{PCl}, n(\%)$ & $23(11.5)$ \\
\hline Cardiac surgery, $n(\%)^{\mathrm{a}}$ & $19(9.5)$ \\
\hline Cardiac arrest, $n(\%)$ & $2(1.0)$ \\
\hline Stroke/TIA, $n(\%)$ & $9(4.5)$ \\
\hline Post-Ml heart failure, $n(\%)$ & $40(20.0)$ \\
\hline Post-Ml atrial fibrillation, $n(\%)$ & $15(7.5)$ \\
\hline Angina pectoris $\mathrm{CCS} \geq 2, n(\%)$ & $34(17.0)$ \\
\hline
\end{tabular}

medication was administered to $75 \%$ of the patients. For other medications, $96 \%$ of the patients were treated with antiplatelet medicines, $83.0 \%$ with beta-blockers and $88.5 \%$ with statins. Only $3.5 \%$ of the whole study cohort achieved all six secondary preventive goals 2 years after AMI (Tables 5, 6, and Fig. 2).

\section{Development of risk profile 2 years after AMI}

As shown in Table 5, there were more individuals that reached the goals of secondary prevention 2 years after the index AMI than at the time of AMI in terms of smoking, LDL reduction, blood pressure control and physical activity (Table 5). Moreover, there was a tendency towards increased BMI 2 years after the index AMI. The proportion of patients with BMI $>30 \mathrm{~kg} / \mathrm{m}^{2}$ increased from $17.5 \%$ at the time of the index AMI to $25.5 \% 2$ years later.

\section{Discussion}

In the present study the six secondary preventive goals were achieved by only $3.5 \%$ of the patients 2 years after the AMI event. Adherence to cardio-protective

Table 5 Development of a risk profile at the time of AMI and at the 2-year follow-up interview

\begin{tabular}{lll}
\hline & At AMI & $\begin{array}{l}\text { At the 2-year } \\
\text { follow-up interview }\end{array}$ \\
\hline No smoking $n(\%)$ & $155(77.5)$ & $175(87.5)$ \\
$\mathrm{LDL}$ cholesterol $<1.8 \mathrm{mmol} / \mathrm{L} n(\%)$ & $8(4)$ & $37(18.5)$ \\
$\mathrm{HbA} 1 \mathrm{C}<4.8 \mathrm{mmol} / \mathrm{mol} n(\%)$ & $\mathrm{NA}$ & $177(88.5)$ \\
$\mathrm{SBP}<140 \mathrm{mmHg} n(\%)$ & $152(76)$ & $114(57)$ \\
Regular exercise training $n(\%)$ & $\mathrm{NA}$ & $90(45.5)$ \\
\hline
\end{tabular}

$N A$ not available, $A M I$ acute myocardial infarction, $L D L$ low density lipoprotein, $S B P$ systolic blood pressure 
Table 6 Comparison of pharmacological treatments at the time of the index $\mathrm{AMl}$ event and at interview 2 years after AMl

\begin{tabular}{lll}
\hline & At AMl & At interview \\
\hline Aspirin $n=200(\%)$ & $199(99.5)$ & $183(91.5)$ \\
Beta-blocker $n=200(\%)$ & $187(93.5)$ & $166(83.0)$ \\
ACE-inhibitor or Angiotensin & $177(88.5)$ & $153(76.5)$ \\
receptor blocker $n=200(\%)$ & & \\
Statin $n=200(\%)$ & $193(96.5)$ & $177(88.5)$ \\
Clopidogrel/prasugrel $n=200(\%)$ & $179(89.5)$ & $11(5.5)$ \\
\hline
\end{tabular}

$A M I$ acute myocardial infarction, $A C E$ angiotensin-converting enzyme

medications, however, was generally good. Still, non-fatal cardiovascular events occurred in $46.5 \%$ of the cohort and cardiac readmissions in $30 \%$ at the 2-year follow-up.

Our study is an extension of the EUROASPIRE survey and the Secondary Prevention after Heart Intensive Care Admission (SEPHIA) Registry in Sweden. EUROASPIRE IV was a cross-sectional study carried out in 24 European countries. Patients included in that study were those with either acute coronary syndrome or elective revascularization in the form of balloon angioplasty or coronary artery surgery. The starting date for identification of an event was $\geq 6$ months and $<3$ years before the expected date of the study interview [8]. The SEPHIA Registry is an on-going Swedish quality registry of AMI patients that focuses on four preventive goals (smoking cessation, optimal control of blood pressure, cholesterol and glucose) and data on the patients are collected during the first year after an AMI. Patients older than 75 years of age are not included in the Registry. Patients are invited to be interviewed by either a registered nurse or physician during an outpatient visit or via a telephone call on two occasions: 4-10 weeks (mean 56 days) and 12-14 months (mean 399 days) after myocardial infarction [9].

Our findings extended available observations by showing divergent development of risk factors from shortterm to long-term time frame after AMI. Firstly, our study confirmed some observations from previous shortterm studies. For instance, regular physical activity is a

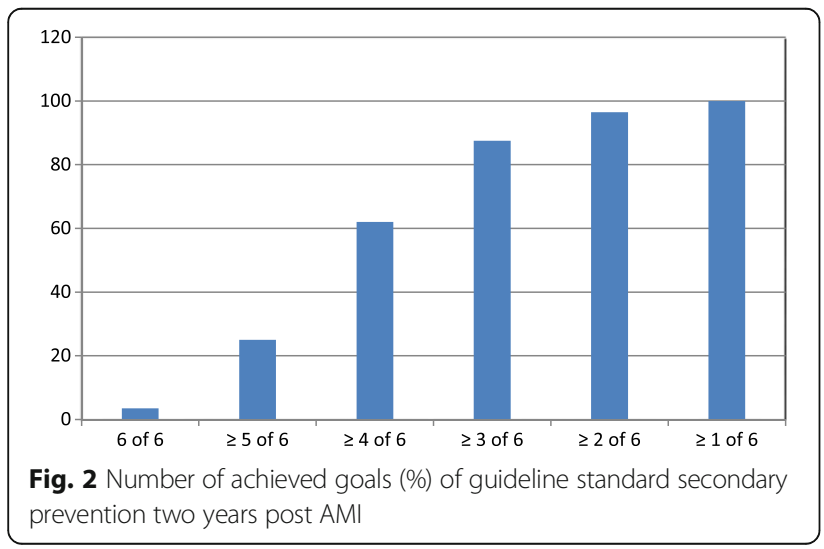

secondary preventive goal that may be hard to achieve. In the EUROASPIRE IV survey only $40 \%$ of the participants attained a physical vigorous intensity level for at least 20 min one or more times per week [8]. In Sweden, the overall participation rate in exercise training within cardiac rehabilitation programs 1 year post-AMI is $51 \%$ [9]. Two years after AMI, $45.5 \%$ of our patients reported participating in moderate regular exercise that caused them to perspire. Thus, it appears that, as in the rest of Europe, a comparable number of our Swedish patients with coronary artery disease participate in cardiac rehabilitation. Furthermore, in our study physical exercise during leisure activity was comparable with that observed in the EUROASPIRE IV. Another example is smoking habit. Regrettably, despite that smoking cessation reduces the risk of a new myocardial infarction [16], about one third of the patients still smoked in EUROASPIRE IV survey study [8]. A similar trend was seen in the Swedish myocardial infarct registry [9] 1 year after the index AMI. Our study suggests that there is an improvement in the number of patients who quit smoking from the index AMI, since $87.5 \%$ of the study participants were classified as non-smokers 2 years after AMI. However, it is not clear whether the improved smoking cessation rate observed in our cohort could be attributed to an increase in the death rate in those patients that did continue smoking but did not survive long enough to be invited. The better results could therefore simply reflect a selection bias in our cohort because participation rates were low. Finally, guideline-directed medical therapy and glucose control 2 years after AMI were in accordance with those reported in EUROASPIRE IV [8] and SEPHIA [9], except that double anti-platelet therapy was indicated only 1 year after AMI and thus could not be adequately evaluated after 2 years.

Secondly, our study provided new information about negative developments in some risk factors from previous short-term studies. Compared with SEPHIA (9), our findings demonstrated failure of long-term secondary prevention as shown by decreased goal achievement in $\mathrm{LDL}<1.8 \mathrm{mmol} / \mathrm{L}$ from $51 \%$ in SEPHIA to $18,5 \%$ in our study, and in blood pressure control with SBP of $<140 \mathrm{mmHg}$ from $73 \%$ in SEPHIA to $57 \%$ in our study, notwithstanding that guideline-directed medical therapy were similar regardless of short or long term after AMI. However, caution must be taken because two studies are not fully comparable.

\section{Limitations}

Our study has some limitations. Patients who were too sick or disabled to attend the study visits could not participate. Moreover, patients who did not speak or understand Swedish were excluded. It is possible that this category of patients may show less compliance and thus 
if they had been included, the goal achievements might have been even lower. Furthermore, in our study, more STEMI than NTSEMI were included despite NSTEMI constitutes the majority of ACS. There are two possible explanations: 1) the majority of the participants (87\%) in our study were hospitalized at Sahlgrenska University Hospital at the time of their index event, the only hospital in Gothenburg with round-the-clock service for PCI, thus more STEMI than NTSEMI were included 2) many patients with NSTEMI have more co-morbidity and thus more hospital visits. This might explain why they were less interested in participating in the study since it means additional hospitals visits. Finally, we could not interview the patients who died during the 2 years that passed between the index AMI and the study inclusion stage. These patients were probably less compliant with the secondary prevention interventions than those who were included in the study. Thus, our results, if anything, may exaggerate the number of persons who potentially achieve secondary prevention goals, further underlining the fact that much could be gained in this area with better adherence to guidelines. Finally, this study was not powered to investigate cause-effect relationship between cardiovascular events and secondary prevention.

\section{Conclusion}

Secondary prevention 2 years after AMI proved suboptimal in our cohort of patients. Only $3.5 \%$ of our patients attained all six secondary prevention goals. Therefore, there is considerable potential to raise the standard of preventive cardiology care through more effective lifestyle intervention and to more rigorously control of risk factors. Perhaps most importantly we need to increase awareness of the current situation and improve regular follow up. Such an effort should help to reduce cardiovascular morbidity and mortality in this patient group.

\section{Abbreviations}

ACE: Angiotensin-converting enzyme; AMl: Acute myocardial infarction; ARB: Angiotensin II receptor blockers; BMI: Body mass index; CABG: Coronary artery bypass grafting; DBP: Diastolic blood pressure; HDL: High-density lipoprotein; ICD-10: The International Classification of Diseases; LDL: Low-density lipoprotein; PCl: Percutaneous coronary intervention; SBP: Systolic blood pressure; STEMI: ST-segment elevation myocardial infarction; TIA: Transient ischemic attack

\section{Acknowledgements}

None.

\section{Funding}

This is an investigator-initiated study supported by the Swedish Heart-Lung Foundation, the Swedish agreement between the government and the county councils concerning economic support for providing an infrastructure for research and education of doctors, the Regional Development Fund, Västra Götaland County, Sweden (FOU-VGR).

\section{Availability of data and material}

The dataset supporting the conclusions of this article are included within the article. The datasets during and/or analysed during the current study available from the corresponding author on reasonable request.

\section{Authors' contributions}

CE engaged in followings: study design, discussion of protocol, statistical analyses, result interpretation, discussion, writing manuscript. ET engaged in followings: study design, ethical application, discussion of protocol, participation of examinations and interview, statistical analyses, discussion, writing manuscript. AR engaged in followings: study design, ethical application, discussion of protocol, result interpretation, discussion, writing manuscript. LB engaged in followings: study design, ethical application, discussion of protocol, result interpretation, discussion, writing manuscript. KBB engaged in followings: study design, ethical application, discussion of protocol, result interpretation, discussion, writing manuscript. KF engaged in followings: study design, ethical application, discussion of protocol, result interpretation, discussion, writing manuscript. MF study design, ethical application, discussion of protocol, result interpretation, discussion, writing manuscript.

\section{Competing interests}

The authors declare that they have no competing interests.

\section{Consent for publication}

Not applicable.

\section{Ethics approval and consent to participate}

This study complies with the Declaration of Helsinki [15] and the study protocol was approved by the Regional Ethical Review Board at the University of Gothenburg (Dnr 325-12). Written informed consent was obtained from each participant by the principal investigator. The research assistants signed the Case Report Form to confirm that informed consent was obtained.

\section{Author details}

${ }^{1}$ Department of Molecular and Clinical Medicine, Institute of Medicine, Skövde, Sweden. ${ }^{2}$ Institute of Health and Care Sciences, Sahlgrenska Academy, University of Gothenburg, Skövde, Sweden. ${ }^{3} \mathrm{R} \& \mathrm{D}$ Centre Skaraborg Primary Care, Skövde, Sweden. ${ }^{4}$ Department of Medicine, Section of Cardiology, Sahlgrenska University Hospital/Östra, 41651 Göteborg, Sweden.

Received: 16 June 2016 Accepted: 7 November 2016

Published online: 17 November 2016

\section{References}

1. Graham I, et al. European guidelines on cardiovascular disease prevention in clinical practice: full text. Fourth Joint Task Force of the European Society of Cardiology and other societies on cardiovascular disease prevention in clinical practice (constituted by representatives of nine societies and by invited experts). Eur J Cardiovasc Prev Rehabil. 2007;14 Suppl 2:S1-S113.

2. Smith Jr SC, et al. AHA/ACC guidelines for secondary prevention for patients with coronary and other atherosclerotic vascular disease: 2006 update: endorsed by the National Heart, Lung, and Blood Institute. Circulation. 2006;113(19):2363-72.

3. Perk J, et al. European Guidelines on cardiovascular disease prevention in clinical practice (version 2012). The Fifth Joint Task Force of the European Society of Cardiology and Other Societies on Cardiovascular Disease Prevention in Clinical Practice (constituted by representatives of nine societies and by invited experts). Eur Heart J. 2012;33(13):1635-701.

4. Bauters $C$, et al. Prognostic impact of ss-blocker use in patients with stable coronary artery disease. Heart. 2014;100(22):1757-61.

5. Berger JS, Brown DL, Becker RC. Low-dose aspirin in patients with stable cardiovascular disease: a meta-analysis. Am J Med. 2008;121(1):43-9.

6. Cooney MT, et al. Determinants of risk factor control in subjects with coronary heart disease: a report from the EUROASPIRE III investigators. Eur J Prev Cardiol. 2013;20(4):686-91.

7. Kotseva $\mathrm{K}$, et al. Cardiovascular prevention guidelines in daily practice: a comparison of EUROASPIRE I, II, and III surveys in eight European countries. Lancet. 2009;373(9667):929-40. 
8. Kotseva K, et al. EUROASPIRE IV: A European Society of Cardiology survey on the lifestyle, risk factor and therapeutic management of coronary patients from 24 European countries. Eur J Prev Cardiol. 2015;23(6):636-48.

9. Hambraeus $K$, Tyden P, Lindahl B. Time trends and gender differences in prevention guideline adherence and outcome after myocardial infarction: Data from the SWEDEHEART registry. Eur J Prev Cardiol. 2015;23(4):340-8.

10. Jernberg T, et al. Cardiovascular risk in post-myocardial infarction patients: nationwide real world data demonstrate the importance of a long-term perspective. Eur Heart J. 2015;36(19):1163-70.

11. Thygesen $\mathrm{K}$, et al. Third universal definition of myocardial infarction. Eur Heart J. 2012;33(20):2551-67.

12. Rosengren A, Tibblin G, Wilhelmsen L. Self-perceived psychological stress and incidence of coronary artery disease in middle-aged men. Am J Cardiol. 1991;68(11):1171-5.

13. Saltin B, Grimby G. Physiological analysis of middle-aged and old former athletes. Comparison with still active athletes of the same ages. Circulation. 1968:38(6):1104-15.

14. Campeau L. The Canadian Cardiovascular Society grading of angina pectoris revisited 30 years later. Can J Cardiol. 2002;18(4):371-9.

15. World Medical Association. World Medical Association Declaration of Helsinki: ethical principles for medical research involving human subjects. JAMA. 2013:310(20):2191-4.

16. Chow CK, et al. Association of diet, exercise, and smoking modification with risk of early cardiovascular events after acute coronary syndromes. Circulation. 2010;121(6):750-8.

\section{Submit your next manuscript to BioMed Central and we will help you at every step:}

- We accept pre-submission inquiries

- Our selector tool helps you to find the most relevant journal

- We provide round the clock customer support

- Convenient online submission

- Thorough peer review

- Inclusion in PubMed and all major indexing services

- Maximum visibility for your research

Submit your manuscript at www.biomedcentral.com/submit 